Milena HAZLER-PAPIČ

\section{Settlement as a physical system and topic in physical planning - basic concepts}

\section{Recent understanding of settlement in the physical planning process}

With the recently adopted Strategy of spatial development of Slovenia, the Republic of Slovenia's long-term plan's fifteen-year period [1], of which only the physical planning part was valid since 1991, is coming to an end. In this document the field of settlement was dealt with as the urban network concept and rather statically. Centres of national, regional and local importance were defined as compulsory components of the national plan. Amendments to the longterm plan in 1999 [2] proclaimed all settlements as compulsory components, implying, amongst other, harmonisation of settlement development on the local level with the national physical plan.

\section{Settlement terminology before transition to the new planning and legislative period}

The terminology used for settlements in the long-term national plan and municipal plans is derived from the former Law on physical planning (LPP, 1984), especially the parts stipulating the settlement network and its areas (article 5) and those directing new settlement into management areas of settlements (article 17). The latter are defined as "compact built-up areas and other areas of the extant settlement or new areas, which are intended for planned development of the settlement or groups of settlements " (article 33). From the stated, the former planning laws were clearly rather meagre and careful in defining concepts dealing with settlement, but above all they refrained from legal-formal use of the term settlement. In this sense the national longterm plan specifies "centres «, while its amendments (1999) emphasised »management areas of settlements «, to which new development was directed.

The new Law on physical planning (NLPP, 2002) [3] has definitions of basic concepts in article 2. Nevertheless, the definition of settlement was rather carelessly drawn as builtup compact area. Such ambiguous definition of the concept of settlement has produced significant prejudice. Not only is the definition and used concept professionally unclear, when tied to settlement and physical planning, it is also inconsistent with the definition used in the law on names and evidences of settlement, streets and buildings (LNESSB, 1980) [4], which in article 2 stipulates that a settlement is "a compact or dispersed group of buildings that compose an inhabited territorial unit (town, market, village, industrial settlement, spa etc.), that have a common name, own system of numerating buildings and a defined area formed by one or more statistical units «. NLPP added to this shaky basis, i.e. "new settlement", two more concepts: settlement area $-" .$. are areas of settlements and areas provided for their growth that are, as such, defined in planning acts «. Contrary to the former law, the concept management areas of settlements is given a new role, now seen as "a physically and functionally uniform area that is managed by the regional concept of physical development, urbanistic or landscape concept and the location plan (article 2). Furthermore, spatial arrangement is defined as planned distribution of activities and buildings in a given management area.

Funny enough, NLPP amongst the definitions in article 2, didn't add the term settlement to the concept space (equivalent to nature), spatial development, spatial arrangement, spatial management and spatial (physical) planning, although there is a definition of landscape, which is apparently part of space, characterised by the dominant presence of natural elements and is the result of mutual interaction and influence of natural and man-made factors. In short, there is nothing about settlement as a spatial system that (actually) "produces « (cultural) landscape. According to Lah (1995), cultural landscape is sterritory settled and changed by human action «, while VSL (Great Slovene Lexicon) defines settlement as "process of land usage for permanent settlement of humans, as well as conditions of such use; natural circumstances and social-economic level of development define the physical settlement structure (cultural landscape)«. [5]

The obvious reason for lack of a definition for settlement in the law itself is its un-comprehensive approach, i.e. an approach that would ensure achievement of general and concrete goals concerning settlement development and the physical settlement system. These goals are: preservation and distinction of its elements and structures, links to other spatial components and comprehensive overview of its development with respect to principles of sustainable development.[6] Proposals for adequate definitions of concepts pertaining to settlement can be derived only from a comprehensive approach.

\section{Settlement as a spatial system and spatial component}

Natural and anthropogenic spatial systems

Man (Greek anthropos) creates anthropogenic physical systems in the natural physical system. Because of the presence and actions of man the natural physical system is changed and adapted thus gaining qualities of a cultivated natural system, which is complemented with anthropogenic elements, i.e. elements of the settlement system. This changed natural entity (nature + man), which emerges as a subsystem to the natural system, is generally known as cultural landscape.

\section{Spatial systems as spatial components}

In the physical planning process numerous natural and anthropogenic physical systems meet, which could be joined under a common term "physical components «, joining both natural and man-made created physical components. [7] By connecting so-called physical components into sensibly connected groups, physical planning practise has introduced "working « definitions for different groups of physical systems (settlement, infrastructure, landscape). 
Spatial systems in the physical planning process

In the proposal of basic spatial systems dealt with in the physical planning process certain terms that are already used in the field and practise have been adopted (cultural landscape, settlement), but a need emerged for complementing the established nomenclature with an additional system, so-called cultivated nature (Hazler-Papič 2003). With this concept cultural landscape is cleared off "all interventions in nature and its transformation, which are a consequence of human settlement, and which are not building of settlements or buildings, but are transformation of nature for economic or any other process «. By defining this spatial system we can define the working of the system of settlements with more precision, its links to the cultural landscape system and explain their often un-harmonised behaviour.

The main spatial systems, which are the subject of physical planning processes, are:

- Natural spatial systems,

- Anthropogenic spatial systems.

Anthropogenic spatial systems are:

- System of settlements (immediate anthropogenic spatial system),

- System of cultivated nature,

- Cultural landscape system (wider anthropogenic spatial system).

\subsection{Settlement systems}

If nature is the primary spatial system, settlement is the secondary system and cultural landscape the third spatial system. The settlement system is an anthropogenic system in the immediate sense, while cultural landscape is an anthropogenic spatial system in the wider sense. The cultural landscape system is hierarchically the highest anthropogenic spatial system. Settlement is the built-up part of the spatial system containing buildings (objects) and links between them; it is man-made and created by transformation of natural spatial components. We can state that settlement is the part of anthropogenic spatial systems, which in view of physical changes and transformations is the only active system that also affects formation of the system of cultivated nature and cultural landscape.

\subsection{Analyses of settlement systems}

\section{Register of buildings}

The basis for any research are evidences. For purposes of reseraching settlement the main parts/elements are - buildings (objects, instalations). Architectural research dealing with the subject is often systematic, demanding and lengthy. Thus also expert guidelines for physical planning acts usually skip this phase, although on the level of urbanism and physical planning intermediate and higher levels are tackled. In the field of settlement therefore, recognition of the system's elements should be undertaken comprehensively, implying interdisciplinary working teams.

\section{Determining structures}

Relations between the system's elements vary thus forming the system's structure. Settlement structures vary according to type. ${ }^{[8]} \mathrm{A}$ common criterion in determining settlement structures is density of elements in the structure. Based on this criterion, settlements are formed by dense (compact) and sparse (dispersed) structures, including their mutual connections.

Contrary to the procedure for noting elements of the system, whereby the researcher's role is obtaining knowledge, definition of the system's structure is more dependent on the reseracher's decisions and results from "a view at the system «. According to systems theoreticians this is "part of the creative research process and remains in the domain of intuitive procedures « (Kljajić 1984:21). Relations between elements are structural, process-based and physical-time dependent (Mulej 1992:68). Such relations emerge in settlement structures - settlements. ${ }^{[9]}$ In any case, the word structure applies to the system and to the type of organisation of its elements in the whole. The structure changes in conjunction with the goals and environment, thus ensuring the system's optimal functioning.

The term "settlement " is not accurate enough to be used in systems analyses. A major deficiency in the definition of "settlement « as part of the settlement system is that it is not defined as as area, but as a structure, and that it is once defined as an area and then as a structure. According to the systems theory, terms shouldn't be confused, since they have completely different properties: structure is defined by the reseracher's criteria, while the area can be equated to the system.

\section{The system as an entity of many parts}

The system can be intuitively understood as a whole, composed of elements that can all influence the system's properties, but none can independently affect changes of the whole or can any sub-system independently affect the working of the whole (Acoff 1994). The system is a whole that is larger than the sum of its components and cannot be reduced to them (Russel's paradox). The natural system is the settlement system's environment.

\section{Issues in conceptual annotations in the field of settlement}

Conceptual annotations for settlements are mostly common, agreed upon or enforced. However settlement or inhabitation are such primeval matters, that used day-to-day terms mix with terminology used by different disciplines in different activities. Expert annotation doesn't always have singular meaning, which causes certain problems. Therefore explanation of meanings is welcome in any discourse.

The terms »building «, »object« and "settlement" The most often used terms when speaking about settlement are object, building and settlement. For the physical planning process it is important, hoe they are defined in valid laws: in the Law on registering property, the national border and territorial units (LRPNBTU) for example, it is stipulated that in the buildings cadastre data about buildings and parts of buildings is noted, whereby article 58 defines that "a building is an object that can be entered and used for permanent or occasional dwelling, conduct of business and other activities or sheltering, which cannot be moved without damage to its substance «[10] Settlement is defined in the Law on names and evidences of settlement, streets and buildings (LNESSB). The term »object« cannot be found in the mentioned laws as a synonim for building; it is a wider concept and therefore cannot be so narrowly defined. 
The stated definitions provide some support to the term settlement, but aren't suitable for what one could call "settlement terminology«. Therefore it would be beneficial for settlement research to devise an independent terminology, which could tie fundamental and applicative research in this field.

Defining buildings and settlements as spatial units Settlements are legally defined by law as territorial (spatial) units (LRPNBTU). Such definition is acceptable for recognising and researching units in the settlement system, since it leaves no leftover vacant space. All the territory is covered by settlement areas as spatial units. Space is defined by the settlement's cipher, which is furthermore tied to the munipality's cipher, thus singularly identifying the territory of every settlement in the country. Anything that "happens " on a settlement's territory, which is defined by law, can be noted by the department of settlement and recognised as a (basic or superior) settlement unit, which is tied to the settlement territory's universal cipher. The territory of any settlement therefore has its identifier (as a statistical area and territorial unit), which applies to the whole Slovene territory. The common connecting code-book for units of the settlement system is thus the settlement's territory, which has a name, statistical cipher and territory, defined by LRPNBTU.[11]

Buildings with house numbers are linked to the settlement unit according to the system of territorial units, via the buildings register or cadastre. However, if the definition of settlement as a territorial unit according to the two laws (LRPNBTU and LNESSB) is adequate for settlement evidences, the definition of buildings as units annotated in the buildings register is too narrow. The adequate database will therefore have to be devised in the department of settlelment as a database of all settlement elements and linked to suitable registers of territorial units.

\section{Naming settlement units in physical planning}

According to the present departmental working method, settlement units are not annotated as the extant condition of settlement, which is independent of the planning process, but only in connection to preparation of planning acts. Hereby a settlement unit's limits in fact equate to the so-called settlement management area. In certain interpretetions this is also the limit of the settlement body itself, the recognised spatial unit is a condition, expanded for »development purposes «.[12]

The planned »management area's « limit therefore hides or conceals the essence of everything "that has happened and will happen in the settlement«. In other words, it is impossible to establish typologies and categories of particular settlement units, nor is it possible to compare the planned development step with the unit's starting condition. Separation of these two steps is therefore inevitable and the term "management area «, which is tied to changes of conditions, has to be complemented woth data about the state of the settlement unit (evidences!). Such data is a constitutive part of a departmental database (data register) and is essential information about the system's condition, whose caretaker the department is. ${ }^{[13]}$

\section{Proposal of conceptual terms in the field of settlement}

Starting points

The proposal stems from used and agreed annotation, which are grouped into sensible entities. The most com- monly used term is settlement (noun), other terms are to inhabit and to settle or colonize (verb). Distinction between the two latter terms is necessary [14] for deriving annotations used for structures in the settlement system, whereby the first applies to all structures and the latter to the whole, for example, to settle a given area and not to inhabit a given area. When speaking about inhabiting, we can already describe its nature, i.e. typology of structures and elements, and when we speak about settling or colonizing, only the fact that an area is marked as occupied.

\section{Naming the area of interest}

In discourse the settlement area is always arbitrary, but has to be marked consistently. The term used for any real area that is being reserached from the aspect of recognition of the settlement system is area of settlement (AOS). In the next step these areas are further divided into settlement centres and settlement areas. AOS nevertheless implies that the area of discourse is dealt with as an entity and comprehensively from the aspect of settlement, while being simultaneously seen as part of the settlement system.

Area of settlement $(\mathrm{AOS})=>$ part of the settlement system (area of interest)

\section{Naming settlement elements and structures}

In basic research a researcher is relatively independent when defining terms. The statement is true even for settlements. However usage of evidences from basic research in professional work on aplicative and expert projects is beneficial. Basic research work is truly the best basis for so-called departmental evidences, if it is done in a fashion, whereby the results can be used with relative ease.

The proposed term for settlement elements is settlement object (SO). The term is new and includes all construction tied to settlement. Because of its neutral form it is a suitable basis for primary evidences, which are later typologically classified. It differs from the generally used term "building ", which is too narrow for reseraching settlement or "object «, which is too general. Data on settlement objects should be maintained by the department of settlement, in the register of settlement objects.

Settlement object $(\mathrm{SO})=>$ any construction tied to settlement

Proposed annotation of terms for structures in the settlement system: the term settlement, which is nowadays used very inconsistently, should be really equated to settling, so that all areas of a settlement (defined as statistical territorial units) truly represent the entire settlement system in a given area. In the next step, the settlement system is divided into separate parts according to density of its elements:

Settlement centre $(\mathrm{SC})=>$ dense structures of the settlement system

Settlement area $(\mathrm{NO})=>$ less dense structures of the settlement system

Difference between the terms area of settlement, settlement area and settlement centre area are that the latter two are used to describe recognised, annotated structures of the settlement system, whose reserached part is 
the settlement area. The distinction should be maintained because it implies two or more research steps, whereby we can apply different criteria in a given, single and accurately defined area of settlement and distinguish various settlement structures. For example, if density of elements is the criterion, the structure can be seen as a settlement centre or settlement area; if the criterion is historical settlement form, the names used are village, market or town; if the criterion is content, the structure can be called secondary residences, spa, shepherd's hamlet etc. They of course need adequate explanations of chosen criteria.

Settlement centres (SC) and settlement areas (SA) are units of the settlement system and are superior to the basic unit, i.e. settlement object (SO). Data about these units is maintained in the register of inhabited objects and register of settlement centres and settlement areas.

Naming settlement in physical planning tasks

In this case annotation has to be respectful for guidelines issued by the department of settlement and terminology used in planning laws. For departmental purposes, the term settlement should equate to a settlement's statistical area, defined in the register of territorial units, whose caretaker is the Surveying and mapping office of the Republic of Slovenia. This register links to other databases important for physical planning: the register of territorial units contains the buildings register, which is tied to the buildings cadastre, land cadastre and possible links to the register of cultural heritage etc.[15]

According to planning laws (LPP, 1984) [16] areas of settlement have specified so-called settlement management areas and other management areas. The proposal for annotation of planning units tied to settlement is as follows: Development areas are defined for selected settlement areas and settlement centres or their parts. Physical development can be understood as "settlement within « extant settlement structures or their expansion, i.e. "settlement outside .

When planning development of chosen settlement centres and settlement areas, pertaining development areas are designated in the physical plan, i.e. management areas (MA), whereby they are granted a certain planning status in view of present and planned land use, state of conservation regimes etc. These management areas can be "new « and differ from the limits of the settlement areas or centres that were identified during basic and aplicative research. Exceptions can be made, so that these areas can be outside settlement areas and centres, but their position can be defined only by specifying the settlement's particular statistical area.

management area $(M A)=>$ densely populated management area (DMA)

management area $(\mathrm{MA})=>$ sparcely populated management area (SMA)

Management areas with dense or sparse population (DMA and SMA) are noted in the register of management areas, maintained by the departement of settlement and department of physical planning. These areas are also used to link areas annotated with regimes of management with various physical planning and development documents.

\section{Proposal for establishing a database on settlement}

\section{Settlement in present official databases}

The departmental field is defined by law and official database about spatial components, whose caretaker the department is. Administrative-legal arrangements of the field should enable overview of its condition and direct the field's development. The data is arranged according to legal proscriptions and is generally publicly accessible.

There is no official databse for the settlement system in Slovenia: there is none on the level of basic evidences, applicative evidences, evidences of units from valid planning documents, and least of all as a register of units of the settlement system. Amongst the expert and governmental publis, views about the necessity of such a register are ambigous. However, on the theoretical level it is possible to develop a conceptual data system for settlements. Hereby one has to ascertain that there are in existence various databases, which can be applied to settlements, but they are not devised in a manner to take aboard the entire data system, which would be collected in the Department of settlement. According to article 72 of the law (LNESSB) these registers are: the buildings register and cadastre and the register of territorial units.

Links between data about elements of the settlement system with other, extant databases, e.g. buildings register and cadaster, cannot be done fully, since the definition of buildings in the law doesn't allow the granting of universal identifiers to all settlement objects, which could be obtained for the field of settlements and annotated.[17]

\section{Proposal for establishing a settlement register}

For the offical settlement's database the basic unit of the settlement system has to be defined, which is given an identifier in the database. Basic elements of the system (basic unit) are defined as the settlement system's basic units. The system's structures are basic units on an hierarchically higher level (superior unit). Amongst the settlement system's secondary units we can place elements of the system's neighbourhood (unit's neighbourhood), which are closely connected to the settlement system's elements, e.g. land parcel.

With this approach, the department of settlement obtains in its register two independent, yet connected databases, i.e two registers: the register of settlement objects and register of settlement centres and settlement areas, which are directly tied to the register of land parcels or land cadaster.

Links between the settlement register and the register of territorial units

The official database for settlements (register of settlements) has to be proscribed by law. This law should also define methods of linkage to other databases, amongst other e.g. the register of immobile cultural heritage.[18] The Law on registering property, the national border and territorial units (LRPNBTU), proscribes links to other databases: article 3 stipulates that: "the land cadastre and buildings cadastre are fundamental evidences of data concerning land and buildings. Other evidences about land and buildings that are maintained by separate governmental bodies, local authority and bearers of public mandates, link to the land cadastre and buildings cadastre, if proscribed 
by law«. These are so-called visiting data, for which the same law stipulates that entry and maintenance of visiting data in the land cadastre and buildings cadastre should be handled by the body responsible for the evidence, in which the data is kept.

If the land cadastre and buildings cadastre are used to connect several databases with similar data, the Surveying office informs responsible authorities about data changes and possible discrepancies between the databases. Negotiating discrepancies between similar data are taken care of by an inter-departmental commission established by the government, whose members are representatives of particular ministries, responsible for maintaining data about property, that link to the land cadastre and buildings cadastre.

In this case visiting data in the land cadastre and buildings cadaster would be data from the settlements register, which would be maintained by the department of settlements and e.g. register of immobile cultural heritage.[19] The problem is that the identification system of the latter two is wider and wouldn't be fully compatible with the buildings register. The umbrella database for noting elements from the settlement system could actually be only the register of settlement objects.

\section{Settlement as a separate departmental field}

Spatial systems are included in the physical planning process by governmental departments. Each department defines and responds to real spatial reality, as well as cocreates it, independently. By obtaining knowledge, a department contributes to creation of spatial policy; it is the indicator and controller of sustainable development in its particular field. A particular department acts as caretaker thorough its spatial component, and is therefore the bearer of preservation of a specific spatial identity. By applying available instruments in the physical planning process it can affect preservation and/or development of such identity.

In this sense, settlement will have to be recognised as a system under the independent jurisdiction and care of a governmental department. Planning settlement development and its integration in the physical planning process will therefore be only one of the aspects of discourse.

Milena Hazler-Papič, MA, Ministry for environment, spatial planning and energy, Office for spatial development E-mail: milena.hazler-papic@gov.si

\section{Notes}

Uradni list (S)RS = Official bulletin of the (Socialist) Republic of Slovenia

[1] Long-term plan of the Republic of Slovenia, for the period 1986 to 2000, Uradni list SRS, No. 1/86 and onwards.

[2] Ordinance on changes and supplements to the spatial components of planning documents of the Republic of Slovenia, Uradni list RS, No. 11/99.

[3] Law on physical planning, Uradni list RS, No. 110/2002.

[4] The Law on names and evidences of settlement, streets and buildings, Uradni list SRS, No. 5/80.
[5] A. Lah, Leksikon okolje in človek, Ljubljana, 1995; VSL Veliki splošni leksikon, DZS, Ljubljana, 1997-98.

[6] According to the Brundtland Commission from 1987, sustainable development is defined as "development, which satisfies the needs of present generations, without compromising the possibilities of future generations in satisfying their needs " (World Commission of Environment and Development). The principle of sustainable development was adopted at the United Nation's conference on environment and development in Rio de Janeiro in 1992.

[7] The term spatial components, used in this article, represents all actual physical elements (forests, minerals, water, soil, natural heritage, cultural heritage etc.), which are the subject of planned land use and physical planning.

[8] The division into urban, rural settlements or spa and mining settlements is typical.

[9] The term "settlement« is purposely put in inverted commas because of its ambiguity, as will be explained further on.

[10] Law on registering property, the national border and territorial units (LRPNBTU, Official bulletin, No. 52/2000).

[11] According to LRPNBTU municipalities propose the limits of settlements; these are included in official data - the register - by the Surveying office. The caretaker of such data is the Surveying and mapping authority of the Republic of Slovenia. With the new ordinance it will be possible to attach databases established by independent departments to the basic database.

[12] Relations between presented conditions and planned settlement development have remained similar even in the new law on physical planning (2002).

[13] The proposed organisation system about data on settlement deals with procedures and contents that can be compared to contents on protection of immobile cultural herita$\mathrm{ge}$, with the distinction that the settlement data system is wider and can also contain the register of immobile cultural heritage.

[14] To settle: provide for somebody to come and live somewhere; to take over a place (Dictionary of Slovene literary language, 1993).

[15] According to article 3 in LRPNBTU, so-called visiting data.

[16] The article uses steadfast terms concerning settlement, as they were defined in the former Law on physical planning (Uradni list SRS, No. 18/84), since they connect an entire generation of national and municipal physical plans. The present terminology, as used in the new Law on physical planning should link to the so-called national and local Strategy of spatial development and Spatial planning order. On the local level however, strategies still haven't been commissioned, or rather, only pilot examples are being produced. They have so far shown many inconsistencies in the field of planning settlement.

[17] The problem emerges also in links to the register of immobile cultural heritage and register of buildings; the first is wider and contains also hayracks, granaries, wells etc., which cannot be defined as buildings in the register of buildings.

[18] The significance of immobile cultural heritage (i.e. institutionally protected cultural heritage) is that in relation to settlement, it is only one of the settlement system's properties of elements and structures. Institutionally protected cultural heritage (IPCH) as an historically marked - achronous, and therefore dependent physical system, cannot dictate the settlement system's "course of development", but is nevertheless one of the most important denominators of distinctness of anthropogenic physical units and therefore its unmistakable element and indispensable part.

[19] Ordinance on the register of immobile cultural heritage, Uradni list, No. 25/2002.

For sources and literature turn to page 12. 